\title{
PREVALENCE OF REFRACTIVE ERROR AND VISUAL IMPAIRMENT AMONG RURAL SCHOOL-AGE CHILDREN OF GORO DISTRICT, GURAGE ZONE, ETHIOPIA
}

\author{
Jafer Kedir ${ }^{1}$, Abonesh Girma ${ }^{2}$
}

\begin{abstract}
BACKGROUND: Refractive error is one of the major causes of blindness and visual impairment in children; but community based studies are scarce especially in rural parts of Ethiopia. So, this study aims to assess the prevalence of refractive error and its magnitude as a cause of visual impairment among school-age children of rural community.

METHODS: This community-based cross-sectional descriptive study was conducted from March 1 to April 30, 2009 in rural villages of Goro district of Gurage Zone, found south west of Addis Ababa, the capital of Ethiopia. A multistage cluster sampling method was used with simple random selection of representative villages in the district. Chi-Square and t-tests were used in the data analysis. RESULTS: A total of 570 school-age children (age 7-15) were evaluated, $54 \%$ boys and $46 \%$ girls. The prevalence of refractive error was $3.5 \%$ (myopia $2.6 \%$ and hyperopia $0.9 \%$ ). Refractive error was the major cause of visual impairment accounting for $54 \%$ of all causes in the study group. No child was found wearing corrective spectacles during the study period.

CONCLUSIONS: Refractive error was the commonest cause of visual impairment in children of the district, but no measures were taken to reduce the burden in the community. So, large scale community level screening for refractive error should be conducted and integrated with regular school eye screening programs. Effective strategies need to be devised to provide low cost corrective spectacles in the rural community.

KEYWORDS: Refractive error, visual acuity, visual impairment, children
\end{abstract}

DOI: http://dx.doi.org/10.4314/ejhs.v24i4.11

\section{INTRODUCTION}

Refractive error is one of the most common causes of visual impairment. Recent data suggests that a large number of people are blind in different parts of the world due to high refractive error because they are not using appropriate refractive corrections (1).

The global magnitude of refractive error is not reliably known, as there is great variation in groupings according to age, definitions of blindness, and examination methods. Reports suggest that $5-25 \%$ of blindness in some countries is caused by refractive errors and as much as $4 \%$ of the population sees less than $6 / 18$ because of this condition (2).

Refractive error as a cause of blindness has not received much attention because many definitions of blindness have been based on best corrected visual acuity (BCVA). However, in many parts of the world, refractive error would become the second largest cause of treatable blindness if blindness were defined on the basis of presenting distance visual acuity (3). This fact is further strengthened by the recent report of global meta-analysis released by WHO in 2008.

\footnotetext{
${ }^{1}$ Department of Ophthalmology, Jimma University, Ethiopia

${ }^{2}$ Department of Ophthalmology, Addis Ababa University Medical Faculty, Ethiopia

Corresponding Author: Jafer Kedir, Email: jafked@yahoo.com
} 
According to this report, a total of 153 million people in the world are estimated to be visually impaired from uncorrected refractive errors, of whom 8 million are blind. This cause of visual impairment has been overlooked in previous estimates that were based on best corrected vision. This revealed that uncorrected refractive error is the main cause of low vision and the second cause of blindness (4).

According to the report from the 'National Survey on Blindness, Low Vision and Trachoma in Ethiopia', that was conducted in the year 20052006, the prevalence of blindness in Ethiopia was $1.6 \%$ and that of low vision (vision $<6 / 18$ ) was $3.7 \%$. But in this survey, emphasis was not given for burden of refractive error in children even though they were included in the general population (5). Special attention should be given to children because visual impairment in children restricts their education and general performance, personality development, future quality of life and career opportunities which affect their success lifelong (6).

There are various ways of assessment of refractive error in children. The two most common ways are community vision screening approach and school vision screening approach. In developing countries like Ethiopia, not all children start schools on time, and impaired vision due to refractive error may even be the reason not to attend schools. So, screening based on schools fail to reach these children and community vision screening may be the best way to include these children.

Only few studies are done on this issue in Ethiopia in some schools. Based on these facts, our study was done with an objective of determining the prevalence of refractive error and its contribution to childhood visual impairments in the school age children of rural community. Other causes of visual impairment were also determined in this study.

\section{MATERIALS AND METHODS}

A community-based, cross-sectional, descriptive study was done from March 1 to April 30, 2009, in children aged 7-15 years living in rural community of Goro District, Gurage Zone of southern Ethiopia. There were 15 districts in Gurage Zone. From these districts, Goro, which is located at about $150 \mathrm{~km}$ southwest of Addis Ababa, was selected for this study taking cost, manpower and time in to consideration. Goro district had a total population of 169,000 . About $45 \%$ of the population comprises of children under 15 years of age and about $20 \%$ of the total $(33,800)$ are in the age range of $7-15$ years $(7)$. Taking in to account the proportion of refractive error in the past related studies in the region $(6.3 \%)$, margin of error $2.5 \%$, and the design effect 1.5 , the calculated sample size was 544 children.

Multistage cluster sampling was used to select the study population. The district was geographically classified in to peasant associations (PAs), which is taken as 1st stage cluster. There were 64 PAs in the district. Six PAs were selected by lottery method from the total list of 64 . In the district, PAs were further divided into villages that have an average of 50 households each. Villages were chosen as second level clusters and 2 villages were selected by simple random selection (lottery method) from each of the 6 peasant associations. So, 12 villages were selected as the final cluster of the study populations. Since the average household size in Ethiopia was estimated to be 5 during the study period, each household was expected to have an average of one child in the age group of 7-15 and every household in the village was visited (8).

All children whose ages were 7-15 years living in these villages were registered by the data collectors and included in the study. This resulted in the involvement of 570 children, which is slightly higher than the calculated sample size. Then, all of them were examined at their respective villages after informed consent was obtained from the parents.

For each eligible child, general information like name, age, gender and years of schooling were recorded before ophthalmic evaluation. The ophthalmic examinations include distance visual acuity measurement, subjective refraction, ocular alignment and motility evaluation, and, anterior segment and fundus examination.

Visual acuity was measured in bright sunlight by Snellen's E-chart at $6 \mathrm{~m}$. For children with uncorrected vision of $6 / 12$ or worse, visual acuity was repeated with pinhole. For children who showed improvement with pinhole, subjective refraction was done using standard refraction trial 
set. For the children with uncorrected vision of $6 / 12$ or worse, but no improvement of vision with pinhole, further evaluation was done which includes: ocular alignment at $0.5 \mathrm{~m}$ and $4 \mathrm{~m}$ (for near and distance vision respectively), ocular motility, anterior segment evaluation using torch light and magnifying loupe, and posterior segment evaluation using direct ophthalmoscope after pupillary dilation by $1 \%$ tropicamide eye drop. Finally, subjective refraction was done for those children with retinal finding suggestive of high myopia but no improvement with pinhole. The principal cause of uncorrected vision of $6 / 12$ or worse was recorded after completion of the ocular examination. The causes were categorized into refractive error, corneal opacity due to any cause, cataract, retinal disorders, amblyopia and other causes.

In this study, subnormal vision was defined as vision of $6 / 9$ or worse in the better eye; visual impairment was defined as vision worse than $6 / 18$ in the better eye. Myopia was considered in refractive error requiring a minus sphere of 0.50 Diopter or more for correction and hyperopia if they need a plus sphere of 1.00 Diopter or more. Amblyopia was diagnosed in children with poor vision which does not improve with refraction and no pathology causing the visual loss.

All data were entered into computers using SPSS software version 16 and processed. Statistical tests of significance were conducted using $\mathrm{x}^{2}$ tests or two tailed $\mathrm{t}$ - tests as appropriate and $p$-values less than 0.05 were considered significant. The study was done after approval by Research and Publication Committee of the Department of Ophthalmology, Medical Faculty of Addis Ababa University. Permission was also obtained from appropriate administrative bodies and stakeholders of the local area. Informed consent was obtained from parents of each child after explaining the procedure and the purpose of the study.

\section{RESULTS}

During the study period, 592 children aged 7-15 years were registered and 570 of them participated in the study, accounting for $96 \%$ response rate. Out of these, $54 \%$ were boys. A total of 375 children $(65.8 \%)$ were in the age range of 7-10 and the remaining 195 (34.2\%) were 11-15 years old (Table 1).

Table 1: Age and sex distribution of the schoolage children in rural Gurage Zone; Mar 1- April 30, 2009.

\begin{tabular}{llll}
\hline & \multicolumn{2}{c}{ Sex } & Total \\
Age group & F & M & \\
\hline 7-9 yrs & 115 & 135 & $250(43.9 \%)$ \\
10-12 yrs & 106 & 137 & $243(42.6 \%)$ \\
13-14 yrs & 41 & 36 & $77(13.5 \%)$ \\
Total & 262 & 308 & $570(100 \%)$ \\
\hline
\end{tabular}

Among the children, the majority $(71.6 \%)$ were in grade 1-3. A total of 34 children (6\%) did not start schooling (Table 2).

Table 2: Distribution of school grade among the rural children of Gurage Zone (Age 7-15 years); Mar 1-Apr 30, 2009.

\begin{tabular}{llll}
\hline $\begin{array}{l}\text { School } \\
\text { Grade }\end{array}$ & Sex & M & Total \\
\hline Didn't start & 16 & 18 & $34(6.0 \%)$ \\
$1-6$ & 243 & 283 & $526(92.3 \%)$ \\
$7-9$ & 3 & 7 & $10(1.7 \%)$ \\
Total & $262(46 \%)$ & $308(54 \%)$ & $570(100 \%)$ \\
\hline
\end{tabular}

A total of 533 children (93.5\%) had presenting vision of $6 / 9$ or better in both eyes. The remaining 37 children $(6.5 \%)$ had presenting vision of $6 / 12$ or worse in one or both eyes. Of these, 20 (3.5\% of the total) had vision of $6 / 12$ or worse in both eyes. A total of 10 children $(1.75 \%)$ had presenting vision worse than $6 / 18$ (Table 3 ). 
Table 3: Distribution of presenting and BCVA* in rural school-age children of Gurage Zone; Mar 1-Apr 30, 2009

\begin{tabular}{lll}
\hline VA groups & $\begin{array}{l}\text { Frequency of } \\
\text { Presenting Visual Acuity } \\
\text { Number (\%) }\end{array}$ & $\begin{array}{l}\text { Frequency of } \\
\text { BCVA*(\%) }\end{array}$ \\
\hline$\geq 6 / 9$ in both eyes & $533(93.5)$ & $546(95.8)$ \\
$\geq 6 / 9$ in the better eye & $17(3.0)$ & $13(2.3)$ \\
$6 / 12-6 / 18$ in the better eye & $10(1.8)$ & $3(0.5)$ \\
$<6 / 18-3 / 60$ in the better eye & $10[1.8]$ & $8(1.4)$ \\
$<3 / 60$ in the better eye & 0 & 0 \\
\hline Total & $570(100)$ & $570(100)$ \\
\hline
\end{tabular}

* Best Corrected Visual Acuity

When the best corrected visual acuity (BCVA) was assessed, 546 children $(95.8 \%)$ had vision of $6 / 9$ or better. Only 24 children $(4.2 \%)$ had BCVA of $6 / 12$ or worse in one or both eyes; 11 of them $(1.8 \%$ of total) in both eyes and 13 of them (2.4\%) in one eye. There was no bilaterally blind child according to WHO criteria, but there were 3 children with unilateral blindness. The distribution of presenting visual acuity did not differ significantly between boys $(\mathrm{M}=0.89, \mathrm{SD}=0.18)$ and girls $(\mathrm{M}=0.86, \mathrm{SD}$ $=0.16)(\mathrm{t}=0.58, \mathrm{p}$-value $=0.56$ for the right eye, $\mathrm{t}$ test). There was also no statistically significant difference in the mean presenting vision between children who didn't start schools $(\mathrm{M}=0.90, \mathrm{SD}=$ 0.18 ) and those who were at schools in the same age group $(\mathrm{M}=0.89, \mathrm{SD}=0.19)(\mathrm{t}=0.17, \mathrm{p}$-value $=$ 0.87 , right eye, $\mathrm{t}$-test).
Refractive error was the most common cause of both unilateral and bilateral low vision. Out of the 37 children with either unilateral or bilateral low vision, $20(54 \%)$ had refractive error. Among the 20 Children with refractive error, 13 had bilateral involvement. The other major causes of either unilateral or bilateral subnormal visual acuity were retinal causes, corneal opacity, and strabismic amblyopia with proportion of $10.8 \%, 8.1 \%$ and $5.4 \%$ respectively. The cause of poor visual acuity was unexplained in 5 children (13.5\%), but amblyopia was the most likely factor because of absence of any detectable pathology even though it doesn't fulfill the stated criteria to diagnose amblyopia. The causes the unilateral blindness in three children in this study were: congenital cataract, enucleation after trauma, and phthisis bulbi of unknown cause each involving one eye of the three children (Table 4).

Table 4: Causes of low vision, defined as visual acuity of $6 / 12$ or worse, among rural school-age children of Gurage Zone. Mar 1-Apr 30, 2009

\begin{tabular}{lllll}
\hline & \multicolumn{2}{l}{$\begin{array}{l}\text { No. of eyes with } \\
\text { VA of } \leq \mathbf{6 / 1 2}(\boldsymbol{\%})\end{array}$} & $\begin{array}{l}\text { No. of children } \\
\text { With VA of } \leq \mathbf{6 / 1 2} \\
\text { in one or both eyes }(\boldsymbol{\%})\end{array}$ & $\begin{array}{l}\text { Prevalence of VA } \\
\text { O6/12 in one or } \\
\text { both eyes }(\boldsymbol{\%})\end{array}$ \\
\hline Causes & $16(51.7)$ & $17(65.7)$ & $20(54.0)$ & 3.51 \\
Refractive Error* & $4(12.9)$ & $3(11.5)$ & $4(10.8)$ & 0.70 \\
Retinal abn. & $3(9.7)$ & $2(7.7)$ & $3(8.1)$ & 0.53 \\
Corneal Opacity & $1(3.2)$ & $1(3.8)$ & $2(5.4)$ & 0.35 \\
Strab. Amblyopia** & $-1(2.7)$ & 0.18 \\
Phthisic eye & $1(3.2)$ & - & $1(2.7)$ & 0.18 \\
enucleated & $1(3.2)$ & - & $1(2.7)$ & 0.18 \\
cataract & $1(3.2)$ & - & $5(13.5)$ & 0.88 \\
Undefined & $4(12.9)$ & $3(11.5)$ & $37(100)$ & 6.50 \\
Total & $31(100)$ & $26(100)$ & & - \\
\hline
\end{tabular}

\footnotetext{
* 2 children have bilateral amblyopia due to high myopia, ** strabismic amblyopia
} 
Among the children with refractive error, 15 (75\%) were myopic and $5(25 \%)$ of them were hyperopic. Among these children, the mean value refractive error in the right eye was $-1.16 \mathrm{D} \&$ the left eye $0.90 \mathrm{D}$. The difference between the two eyes was not statistically significant. In the same children with refractive error, the mean value in the right eye was $1.88 \mathrm{D}(\mathrm{SD}=3.31)$ in females and $-0.69(\mathrm{SD}=3.83)$ in males. Females tend to be more myopic but the difference was not statistically significant (pvalue $=0.48)$. The overall prevalence of myopia among the children was $2.6 \%$ and hyperopia $0.9 \%$ (Fig 1). No child was wearing corrective spectacles during the study period.

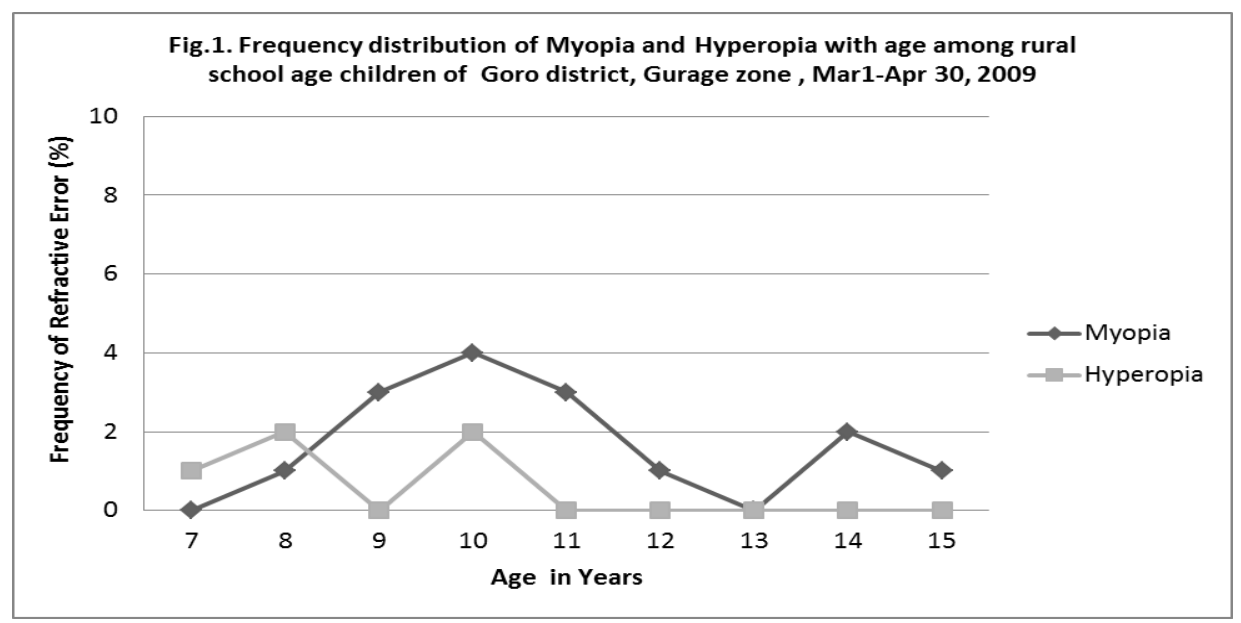

\section{DISCUSSION}

The distribution of refractive error varies in different parts of the world; moreover, there is no uniformly accepted standard way of assessing and reporting the problem until recently. To address this issue, there is a standard protocol set currently, called "Refractive Error Study in Children" (RESC) and carried out in few countries like China, Nepal, Chile, India, Malaysia and South Africa. These studies have shown promising comparable results (4). However, it is difficult to carry out such extensive study in rural community of all countries uniformly because of limited resources and manpower especially in developing countries like Ethiopia. Our study was less extensive but similar to studies done by RESC protocol.

The prevalence of visual impairment in this study (i.e presenting vision $<6 / 18$ ) was $1.8 \%$. This is comparable but slightly lower than that of previous similar study at a school in the district 5 years back which shows visual impairment rate of $2.2 \%$ (9).

The prevalence of low vision in our study (i.e. $3.5 \%$ ) is comparable to that of Iran $(3.8 \%)$ but significantly lower than results of studies in Malaysia (17.1\%), Chile (15.8\%), China (12.8\%), urban India (9.0\%), and to some extent, rural India (5.0\%) (10-15). However, it is higher than the studies done in other countries like Nepal (2.9\%) and South Africa (2.7\%)
(14-15). In another study in rural India, prevalence of low vision was $2.7 \%$ which is slightly lower than ours (15).The major cause of both unilateral and bilateral visual impairment in our study was refractive error. This is similar to most studies done in other countries. The percentage of refractive error from total causes visual impairment ranges from $53 \%$ in Indian studies to $87 \%$ in Iran and $90 \%$ in Tanzanian children of the same age group $(10,15,18)$.

The prevalence of refractive error among the total number of children in our study was $3.5 \%$. This value is very low compared to the study in Uganda, which shows $11.6 \%$ among school children aged 6-9 years (19). It is also lower than that of Iran (6.13\% in age groups $7-15$ years) (8). But it is higher than similar studies in South Africa (1.82\%), India $(1.9 \%)$, and Tanzania $(1 \%)(15,17,18)$.This great variability maybe due to racial/ ethnic variations, different lifestyles, or living conditions in different countries as supported by various prior studies that show significant association between refractive error and these factors $(20-22)$.

The predominant type of refractive error in our study was myopia, accounting for $75 \%$ of the cases. The overall rate of myopia was $2.6 \%$ and hyperopia $0.90 \%$. The prevalence of myopia is lower than the result reported from China (16.2\%), urban India (New Delhi $=7.4 \%$ ), rural India $(4.1 \%)$, and Iran 
(3.4\%) $(10,13-15)$, but it is higher than that of Nepal $(1.2 \%)$ and Tanzania $(0.7 \%)(14,16)$. Our result is similar to that found in South Africa (2.9\%) and Uganda $(2.7 \%)(17,19)$.

The predominance of types of refractive error varies from study to study. In general, objective refraction in children usually shows large predominance of hyperopia. But most of the children have normal vision due to adequate accommodation. In contrast, most of subjective refractions in children with poor vision reveal predominance of myopia in different studies. This observation is compatible with the result of our study.

In conclusion, refractive error was the commonest cause of visual impairment in children of the district, but no measure was taken to reduce the burden in the community. Not a single child was found wearing corrective glasses. As a recommendation, further large scale community level screening of children for refractive error and visual impairment should be done and integrated with regular school eye screening programs. Effective strategies should also be devised to create awareness and provide low cost corrective spectacles for the children in the community.

\section{REFERENCES}

1. Leon B. Ellwen. Case finding in refractive error. Community Eye Health. 2002; 15:43.

2. Developing an action plan: specific disease control strategies. VISION 2020 CD-ROM, chapter 3.

3. World Health Organization. Elimination of avoidable visual disability due to refractive error. 2001; 79:3.

4. Bull. World Health Organ. vol.86 no.1 Geneva Jan. 2008.

5. Yemane B, Alemayehu W, Abebe B et.al. Prevalence and causes of blindness and Low Vision in Ethiopia. Ethiop. J. Health Dev. 2007;21(3):204-210.

6. Brien A Holden. The role of optometry in VISION 2020. 2002; 15(43):33-36

7. CSA (central Statistics Agency of Ethiopia), 2005. National Statistics, Central Statistical Agency, Addis Ababa: Ethiopia.

8. Macro International Inc. 2007. Trends in Demographic and Reproductive Health Indicators in Ethiopia. Calverton, Maryland, USA: Macro International Inc.

9. Mohammed S, Abebe B. Common eye diseases in children of rural community in Goro district, central Ethiopia. Ethiopian Journal of Health Dev. 2005;19(2): 148-152.

10. Akbar F, Hassan H, Mehdi $\mathrm{K}$ et.al. The prevalence of refractive errors among schoolchildren in Dezful, Iran. $B r . J$. Ophthalmol. 2007; 91:287-292.

11. Goh P, Abqariyah Y, Pokharel GP, Leon B. Refractive Error and Visual Impairment in School-Age Children in Gombak District, Malaysia. Ophthalmology. 2005;112:678-85.

12. Maul E, Barroso S, Munoz S, Sperduto R, Ellwein L. Refractive error study in children: $\mathrm{La}$ Florida, Chile. Am J Ophthalmol. 2000;129: 445-454.

13. Zhao J, Pan X, Sui R et.al Refractive error study in children: results from Shunyi District, China. Am J Ophthalmol. 2000; 129:427-435.

14. Murthy GVS, Gupta SK, Ellwein L. Refractive error in children in an urban population in New Delhi. Invest Ophthalmol Vis Sci. 2002; 43:623631.

15. Dandona R, Dandona L, Srinivas $M$ et al. Refractive error study in children in a rural population in India. Invest Ophthalmol Vis Sci. 2002; 43:615-622.

16. Pokharel GP, Negrel AD, Munoz SR, Ellwein LB. Refractive error study in children: results from Mechi Zone, Nepal. Am J Ophthalmol 2000;129:436-44.

17. Naidoo KS, Raghunandan A, Mashige KP et al. Refractive Error and Visual Impairment in African Children, South Africa. Invest Ophthalmol Vis Sci 2003;44:3764-70.

18. Susanne H, David A, Rebecca B. Prevalence of eye diseases in primary school children in a rural area of Tanzania. Br. J. Ophthalmol. 2000;84;1291-1297.

19. Medi K. and Robert M. A survey of the prevalence of refractive errors among children in lower primary schools in Kampala district. African Health Sciences 2002;2(2):69-72.

20. Kleinstein RN, Jones LA, Hullett S, Kwon S et al. Refractive error and ethnicity in children. Arch Ophthalmol 2003; 121: 1141-1147.

21. Rose KA, Morgan IG, Ip J, Kifley A, Huynh S, Smith W, Mitchell P. Outdoor activity reduces the prevalence of myopia in children. Ophthalmology. 2008; 115: 1279-1285.

22. KA, Morgan IG, Smith W, Burlutsky G, Mitchell P, Saw SM. Myopia, lifestyle, and schooling in students of Chinese ethnicity in Singapore and Sydney. Rose Arch Ophthalmol. 2008; 126(4):527-30. 